\title{
Long-range transport of anthropogenic air pollutants into the marine air: insight into fine particle transport and chloride depletion on sea salts
}

\author{
Liang Xu ${ }^{1}$, Xiaohuan $\mathrm{Liu}^{2}$, Huiwang Gao ${ }^{2}$, Xiaohong $\mathrm{Yao}^{2}$, Daizhou Zhang ${ }^{3}$, Lei Bi ${ }^{1}$, Lei Liu ${ }^{1}$, Jian Zhang ${ }^{1}$, \\ Yinxiao Zhang ${ }^{1}$, Yuanyuan Wang ${ }^{1}$, Qi Yuan ${ }^{2}$, and Weijun $\mathrm{Li}^{1}$ \\ ${ }^{1}$ Department of Atmospheric Sciences, School of Earth Sciences, Zhejiang University, Hangzhou 310027, China \\ ${ }^{2}$ Key Laboratory of Marine Environment and Ecology, Ministry of Education, \\ Ocean University of China, Qingdao 266100, China \\ ${ }^{3}$ Faculty of Environmental and Symbiotic Sciences, Prefectural University of Kumamoto, Kumamoto 862-8502, Japan
}

Correspondence: Weijun Li (liweijun@zju.edu.cn)

Received: 22 July 2021 - Discussion started: 29 July 2021

Revised: 28 October 2021 - Accepted: 8 November 2021 - Published: 3 December 2021

\begin{abstract}
Long-range transport of anthropogenic air pollutants from East Asia can affect the downwind marine air quality during spring and winter. Long-range transport of continental air pollutants and their interaction with sea salt aerosol (SSA) significantly modify the radiative forcing of marine aerosols and influence ocean biogeochemical cycling. Previous studies poorly characterize variations of aerosol particles along with air mass transport from the continental edge to the remote ocean. Here, the research ship R/V Dongfanghong 2 traveled from the eastern China seas (ECS) to the northwestern Pacific Ocean (NWPO) to understand what and how air pollutants were transported from the highly polluted continental air to clean marine air in spring. A transmission electron microscope (TEM) was used to find the long-range transported anthropogenic particles and the possible Cl-depletion phenomenon of SSA in marine air. Anthropogenic aerosols (e.g., sulfur (S)-rich, S-soot, S-metal/fly ash, organic matter (OM)-S, and OM coating particles) were identified and dramatically declined from $87 \%$ to $8 \%$ by number from the ECS to remote NWPO. For the SSA aging, $87 \%$ of SSA particles in the ECS were identified as fully aged, while the proportion of fully aged SSA particles in the NWPO decreased to $29 \%$. Our results highlight that anthropogenic acidic gases in the troposphere (e.g., $\mathrm{SO}_{2}, \mathrm{NO}_{x}$, and volatile organic compounds) could be transported to remote marine air and exert a significant impact on aging of SSA particles in the NWPO. The study shows that anthropogenic
\end{abstract}

particles and gases from East Asia significantly perturb different aerosol chemistry from coastal to remote marine air. More attention should be given to the modification of SSA particles in remote marine areas due to the influence of anthropogenic gaseous pollutants.

\section{Introduction}

Marine aerosols play an important role in the global aerosol emission budget and greatly impact the Earth's radiative forcing and biogeochemical cycling (O'Dowd Colin and de Leeuw, 2007). Sea salt aerosol (SSA) is one crucial component of marine aerosols, especially in the remote marine atmosphere (Lewis and Schwartz, 2004). SSA is composed of $\mathrm{Na}$ and $\mathrm{Cl}$, with minor amounts of $\mathrm{Mg}, \mathrm{Ca}, \mathrm{K}$, and $\mathrm{S}(\mathrm{Li}$ et al., 2016a). Fresh SSA usually has the form of a cubic $\mathrm{NaCl}$ core associated with $\mathrm{MgCl}_{2}$ and $\mathrm{CaSO}_{4}$ coating (Chi et al., 2015). SSA in polluted air can serve as reactive surfaces through the uptake of acidic gaseous $\mathrm{SO}_{2}, \mathrm{NO}_{x}$, and organic acids, releasing gaseous reactive chlorine compounds (chloride depletion) (Laskin et al., 2012; Yao and Zhang, 2012). Moreover, the SSA aging processes can transform fresh SSA into partially aged SSA and finally into fully aged SSA that mainly contain $\mathrm{NaNO}_{3}, \mathrm{Na}_{2} \mathrm{SO}_{4}$, and organic sodium salts (Chi et al., 2015; Laskin et al., 2012). These products from the chemical aging processes also modify hygroscopic prop- 
erties of individual SSA (Cravigan et al., 2020; Ghorai et al., 2014). Some studies found that the aged SSA could alter global climate directly by scattering incoming solar radiation or indirectly by acting as cloud condensation nuclei $(\mathrm{CCN})$ or ice nuclei (IN) in marine air (Murphy et al., 1998; Pierce and Adams, 2006; Hu et al., 2005; Kanji et al., 2017; Kong et al., 2018).

It is well known that the interaction of the continentalmarine air masses not only releases some active substances into marine air, but also supplies many nutrients (e.g., Fe, N, and P) for biological growth (e.g., plankton) to the ocean's surface (Li et al., 2017; Shi et al., 2012). Some studies have reported that the continental anthropogenic and natural pollutants can be carried to remote marine air through long-range atmospheric transport (Guo et al., 2014; Li et al., 2017; Moffet et al., 2012; Uematsu et al., 2010). The continental pollutants that are deposited into the ocean increase the nutrient input to the seawater, and finally alter the primary productivity in the open sea (Mahowald et al., 2018; Fu et al., 2018; Luo et al., 2016; Shi et al., 2012). Moreover, previous studies found that large amounts of light-absorbing aerosols (e.g., black carbon and brown carbon) from continental polluted air can be transported into the open ocean air and significantly influence the radiative balance of the marine boundary layer (Ueda et al., 2018; Kang et al., 2018; Zhang et al., 2014; Kondo et al., 2016). Therefore, it is important to understand the physicochemical properties of long-range transported anthropogenic aerosol particles in marine air.

The eastern China seas (ECS: the Yellow Sea and the East China Sea) and the northwestern Pacific Ocean (NWPO) can be affected by the Asian continental air masses under the prevailing westerly winds in winter and spring (Uematsu et al., 2010; Uno et al., 2009). At present, there have been many indepth studies on the physicochemical properties of aerosols in air masses before they leave the Asian continent. For example, Li et al. (2014) collected aerosol particles at a background site in the Yellow River Delta and determined their physicochemical properties before leaving the Asian continent. Feng et al. (2012) studied the sources and formation pathways of $\mathrm{PM}_{2.5}$ at Changdao, a resort island in the Bohai $\mathrm{Sea} /$ Yellow Sea, which is in the transport path of the Asian continental outflow to the Pacific Ocean. Shi et al. (2019) investigated aerosol particles from Asian continental outflow in Qingdao and found that the solubility of phosphorus was related to the sources and atmospheric acidification processes. However, these atmospheric field observations were limited to some isolated continental sites.

Shipboard observations are an effective way to study marine aerosol properties in remote areas. Using the single particle analysis method (i.e., electron microscope), previous shipboard atmospheric studies have observed chloride depletion and sulfur enrichment in SSA particles from the marine boundary layer (McInnes et al., 1994; Mouri and Okada, 1993; Bondy et al., 2017). At a coastal city in southwestern Japan, Zhang et al. (2003) found that dust particles from the
Asian continent could mix with SSA particles in the marine atmosphere and further restrained chloride depletion from the sea-salt component in the particles. However, these studies did not examine how anthropogenic pollutants influence the physicochemical properties of SSA from the margin sea air to the remote marine air. Furthermore, they cannot continuously trace the changes in anthropogenic aerosol particles along the pollutants' transport path to the remote NWPO.

In this study, the research ship R/V Dongfanghong 2 was designed to cruise from the ECS to the NWPO so that we could understand what and how air pollutants are transported from the highly polluted continental air to clean marine air in spring. After the cruise, a transmission electron microscope was used to obtain the composition, size, morphology, and mixing states of marine aerosol particles. Based on this information, we compared aerosol characteristics over the ECS and the remote NWPO. Furthermore, we also discussed how the continental air masses influence marine aerosols in the ECS and the NWPO air.

\section{Experiments}

\subsection{Aerosol sampling and analyses}

Aerosol samples were collected onboard the R/V Dongfanghong 2 during the cruise from 17 March to 22 April 2014. The cruise path crossed the ECS and the NWPO (Fig. 1). Aerosol particles were sampled onto copper transmission electron microscope (TEM) grids (carbon type-B, 300-mesh copper; Tianld Co., China) using a DKL-2 sampler (Genstar Electronic Technology, China). The sampler was equipped with a single-stage impactor with a $0.5 \mathrm{~mm}$ diameter jet nozzle at an airflow of $1.0 \mathrm{~L} \mathrm{~min}^{-1}$. If the particle density is $2 \mathrm{~g} \mathrm{~cm}^{-3}$, the collection efficiency of the sampler is $50 \%$ for particles with a $260 \mathrm{~nm}$ aerodynamic diameter. All the samples were collected at the ship's bow to avoid contamination from the exhaust. During the same cruise, the short-period contribution from contamination of particulate matter was less than $3 \%$ (Luo et al., 2016). The sampling duration varied from 2 to $3 \mathrm{~min}$ to avoid individual particle overlap on the substrate. After the collection, all the samples were sealed in dry plastic capsules and stored in a desiccator at $25^{\circ} \mathrm{C}$ and $20 \pm 3 \%$ relative humidity (RH) for further analysis.

The aerosol particles were analyzed by a JEOL JEM-2100 TEM operated at $200 \mathrm{kV}$. The chemical elements (heavier than carbon, $Z \geq 6$ ) were semi-quantitatively detected by an energy-dispersive X-ray spectrometer (EDS) (Oxford Instruments, UK). Coarser particles are near the center of the sampling spot, and finer particles are on the periphery. Therefore, we selected three or four areas from the center to the edge to guarantee the representativeness of the analyzed particles. The iTEM software (Olympus Soft Imaging Solutions $\mathrm{GmbH}$, Germany) was used to analyze individual particles in 


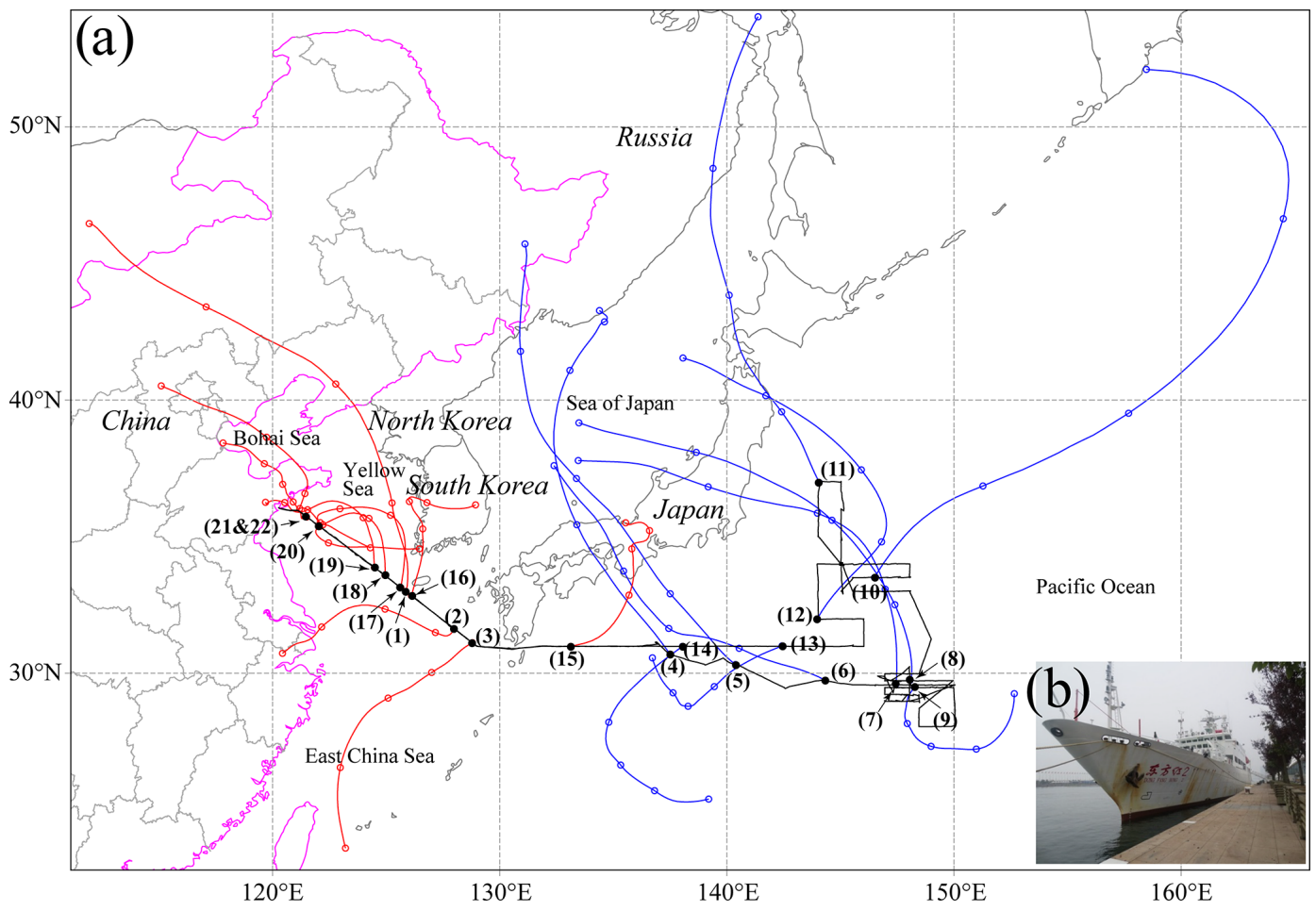

Figure 1. (a) Map of the cruise track (black line) and $48 \mathrm{~h}$ air mass backward trajectories (red and blue lines) arriving at $500 \mathrm{~m}$ above ground level at sampling locations. The interval between two circle symbols is $12 \mathrm{~h}$. The number represents the sample ID in Table S1. (b) Photo of the R/V Dongfanghong 2.

the TEM images and obtain their projected area, perimeter, aspect ratio, and equivalent circle diameter (ECD).

A total of 22 samples were analyzed in this study. The location of each sample is shown in Fig. 1. The details about sampling dates, times, and meteorological conditions for each sample are listed in Table S1. Due to the influence of the westerlies, the ECS is frequently affected by the air pollutants' transport from Asia in spring (Shi et al., 2019). The NWPO is less affected by the transport of continental pollutants because of the remote distance (Zhang et al., 2018). According to the sample locations, we defined two sample categories along with the cruise path (Fig. 1): 11 samples in the ECS and 11 samples in the NWPO.

\subsection{Air mass backward trajectories}

The NOAA HYSPLIT (Hybrid Single Particle Lagrangian Integrated Trajectory) trajectory model (Stein et al., 2015) was applied to calculate the backward trajectories for the investigation of air mass sources and transport paths. The total run time was set at $48 \mathrm{~h}$. We selected an altitude of $500 \mathrm{~m}$ as the endpoint in each backward trajectory. In this study, we obtained 21 backward trajectories.

\section{Results}

\subsection{Classification and relative abundance of aerosol particles}

The TEM analyses provided the morphology, mixing state, and composition of individual particles. In this study, we analyzed 3734 particles in 22 samples (2770 particles collected in the ECS and 964 particles in the NWPO). Aerosol particles were classified into seven types based on their composition and morphology: sulfur-rich (S-rich), organic matter (OM), soot, metal, fly ash, mineral, and sea salt. S-rich particles are considered secondary inorganic particles (e.g., $\left(\mathrm{NH}_{4}\right)_{2} \mathrm{SO}_{4}$ and $\mathrm{NH}_{4} \mathrm{NO}_{3}$ ), which are formed from their gaseous precursors, such as $\mathrm{SO}_{2}, \mathrm{NO}_{x}$, and $\mathrm{NH}_{3}$. OM particles mainly contain $\mathrm{C}$ and certain $\mathrm{O}$ and $\mathrm{Si}$. Here we observed two kinds of OM particles: spherical or irregular primary organic matter (POM) particles and secondary organic matter (SOM) particles. The POM particles are directly emitted from the combustion of fossil fuel and biomass, and SOM particles are formed from volatile organic compounds (VOCs) or the oxidized POM in the atmosphere (Li et al., 2016a; Wang et al., 2021). In the TEM images, the POM particles normally have a spherical or irregular shape. The SOM particles display a core-shell structure, which usually represents an inorganic core (e.g., sulfate) coated by secondary organics (Li et al., 
2016b). Soot particles (i.e., black carbon) are chain-like aggregates of carbonaceous spheres, mainly containing $\mathrm{C}$ and minor $\mathrm{O}$. Metal particles mainly contain $\mathrm{Fe}, \mathrm{Zn}$, and $\mathrm{Pb}$, and fly ash particles contain $\mathrm{Si}, \mathrm{Al}$, and minor $\mathrm{Ca}$ and $\mathrm{Fe}$. Metal and fly ash particles both display spherical shapes and are directly emitted from heavy industrial activities such as power plants and steel factories (Li et al., 2017). Mineral particles are composed of $\mathrm{Si}, \mathrm{Al}, \mathrm{Ca}$, and $\mathrm{Fe}$ and present irregular shapes (Fig. 2a). Mineral particles originate from arid deserts (e.g., Sahara and Gobi), roads, and construction activities in the continental areas. SSA (Fig. 2b) is from the bursting of air bubbles resulting from the waves breaking. SSA is mainly composed of $\mathrm{Na}$ and $\mathrm{Cl}$, with minor $\mathrm{Mg}, \mathrm{Ca}, \mathrm{K}$, and $\mathrm{S}$.

The high-resolution TEM could see through the thin materials on the substrate, so the inner mixing structure of different aerosol components in individual particles can be directly identified (Li et al., 2016b; Riemer et al., 2019). We found that most of the individual non-SSA particles collected in marine air contained two or more different types of anthropogenic aerosols. To elucidate the mixing structure of the non-SSA particles, we further defined six types of internally mixed particles: S-metal, metal particles mixed with sulfate (Fig. 2c); S-fly ash, fly ash particles mixed with sulfate (Fig. 2d); S-soot, soot particles mixed with sulfate (Fig. 2e); OM coating, SOM coated on sulfate (Fig. 2f); OM-S, a POM particle mixed with sulfate (Fig. 2g); and S-rich, secondary inorganic sulfate and nitrate particles (e.g., $\left(\mathrm{NH}_{4}\right)_{2} \mathrm{SO}_{4}$ and $\mathrm{NH}_{4} \mathrm{NO}_{3}$ ) (Fig. 2h). Anthropogenic aerosols are particles originating from human activities, including S-rich, S-soot, S-metal/fly ash, OM-S, and OM coating particles in this study. In the ECS, anthropogenic aerosols accounted for $87 \%$ of all particles by number fraction, including S-rich for $42 \%$, S-soot for $21 \%$, S-metal/fly ash for $8 \%$, OM-S for $6 \%$, and OM coating for $10 \%$. Only $8 \%$ of the observed particles in the ECS were SSA particles. The remaining $5 \%$ were identified as mineral particles. Interestingly, SSA particles became the dominant aerosol at $90 \%$ in the NWPO and anthropogenic aerosols only accounted for $8 \%$, suggesting that marine emissions became the major aerosol source in the NWPO. Therefore, there are large differences between aerosol particles in the ECS and the NWPO (Fig. 3).

\subsection{Variations of aerosol particles from the ECS to the NWPO}

Figure 3 shows variations of aerosol particles along with the cruise pathway from the ECS to the NWPO. Mineral particles can only be transported from continental areas. Figure 3 shows that higher number fractions of mineral particles always occurred when the sampling sites were close to eastern China. The number fraction of mineral particles rose to $15 \%$ in the coastal air during the cruise (Fig. 3). The proportion of mineral particles decreased from $15 \%$ to $3 \%$ for the samples collected in the ECS. When the ship traveled eastward into the NWPO, the proportion of mineral particles dropped to a low level $(2 \%)$. In contrast, the proportion of mineral particles increased again when the ship returned to the ECS. Altogether, the number fraction of mineral particles was $5 \%$ in the ECS, higher than that in the NWPO, suggesting that the ECS and NWPO were influenced by westerlies during the sampling period. Indeed, Fig. 1 shows that most of the $48 \mathrm{~h}$ backward trajectories of air masses in the ECS were sourced from eastern China and that some of the $48 \mathrm{~h}$ back trajectories of air masses in the NWPO crossed Japan.

Figure 3 shows that S-metal and S-fly ash (two typical anthropogenic aerosol particles) displayed variation similar to the mineral particles. Number fractions of S-metal and Sfly ash particles in the ECS samples ranged from $17 \%$ to $2 \%$ with the average value at $8 \%$, but only $0.3 \%$ for Smetal and S-fly ash particles was found in the NWPO. In a word, we conclude that aerosol particles from the Asian continent directly exert much greater impacts on the ECS than the NWPO.

\subsection{Comparison of anthropogenic secondary aerosol particles}

Secondary S-rich and OM coating particles are normally considered to arise from the conversion of anthropogenic gaseous pollutants (e.g., $\mathrm{SO}_{2}, \mathrm{NO}_{x}, \mathrm{NH}_{3}$, and VOCs) ( $\mathrm{Li}$ et al., 2021). TEM observations clearly identified secondary particles and showed their variation of number fraction in the samples (Fig. 3). Our results show that number fractions of S-rich particles were dominant in the ECS samples with the range of $32 \%-71 \%$, but their fractions decreased to $5 \%$ in the NWPO. The results indicate that secondary particles in the ECS were strongly influenced by anthropogenic pollutants transported from eastern China. Furthermore, we noticed that secondary aerosol particles were frequently mixed with some typical fine primary anthropogenic particles (e.g., soot, fly ash, and metal) and formed S-soot/S-fly ash/S-metal particles (Fig. 4). As a result, we conclude that the anthropogenic gases or aerosol pollutants in the continental air masses significantly influence the downwind air quality of the ECS, but they have a minor impact on the NWPO air.

It should be noted that OM coating particles were frequently found in the ECS but barely observed in the NWPO. In other words, S-rich particles in the NWPO had no typical OM coating, although S-rich particles accounted for $\sim 5 \%$ in the NWPO samples. Figure $4 \mathrm{~b}$ shows that these S-rich particles in the NWPO only had one dominant size range smaller than $1 \mu \mathrm{m}$, which is different from the larger and broader size distribution of S-rich particles in the ECS. In addition, we noticed the particularly high fraction of S-rich particles in sample nos. 11 and 12 collected in the NWPO (15\% and $24 \%$ ). Coincidently, Zhu et al. (2019) observed a new particle formation event in the same area and proposed that the event was likely caused by long-range transported continental gases (e.g., $\mathrm{SO}_{2}, \mathrm{NO}_{x}$, and VOCs). 
(a) Mineral
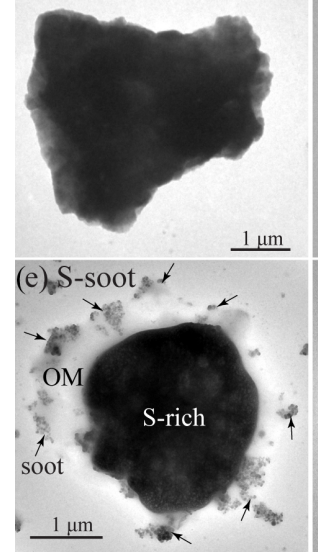
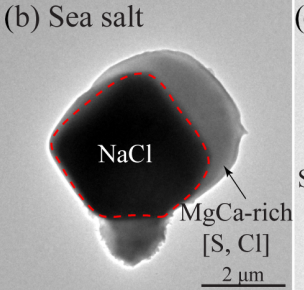

(f) OM coating (c) S-metal

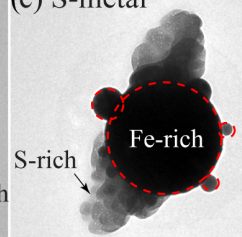

$\underline{500 \mathrm{~nm}}$

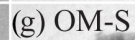

(g) OM-S

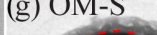

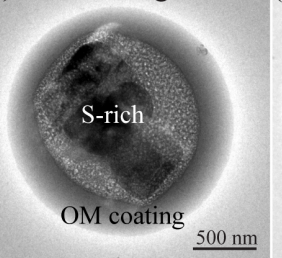

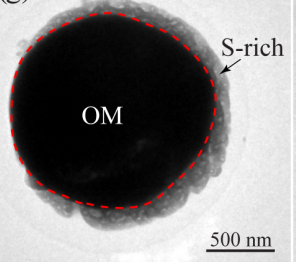

(d) S-fly ash

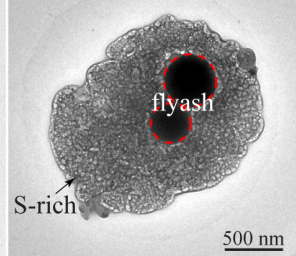

(h) S-rich

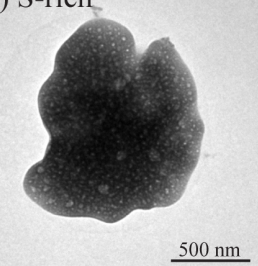

Figure 2. Transmission electron microscope (TEM) images of different types of aerosol particles: (a) mineral; (b) sea salt; (c) metal particles mixed with sulfate; (d) fly ash particles mixed with sulfate; (e) soot particles mixed with sulfate; (f) secondary organic matter (OM) coating on sulfate; (g) primary OM particles mixed with sulfate; (h) S-rich particles.

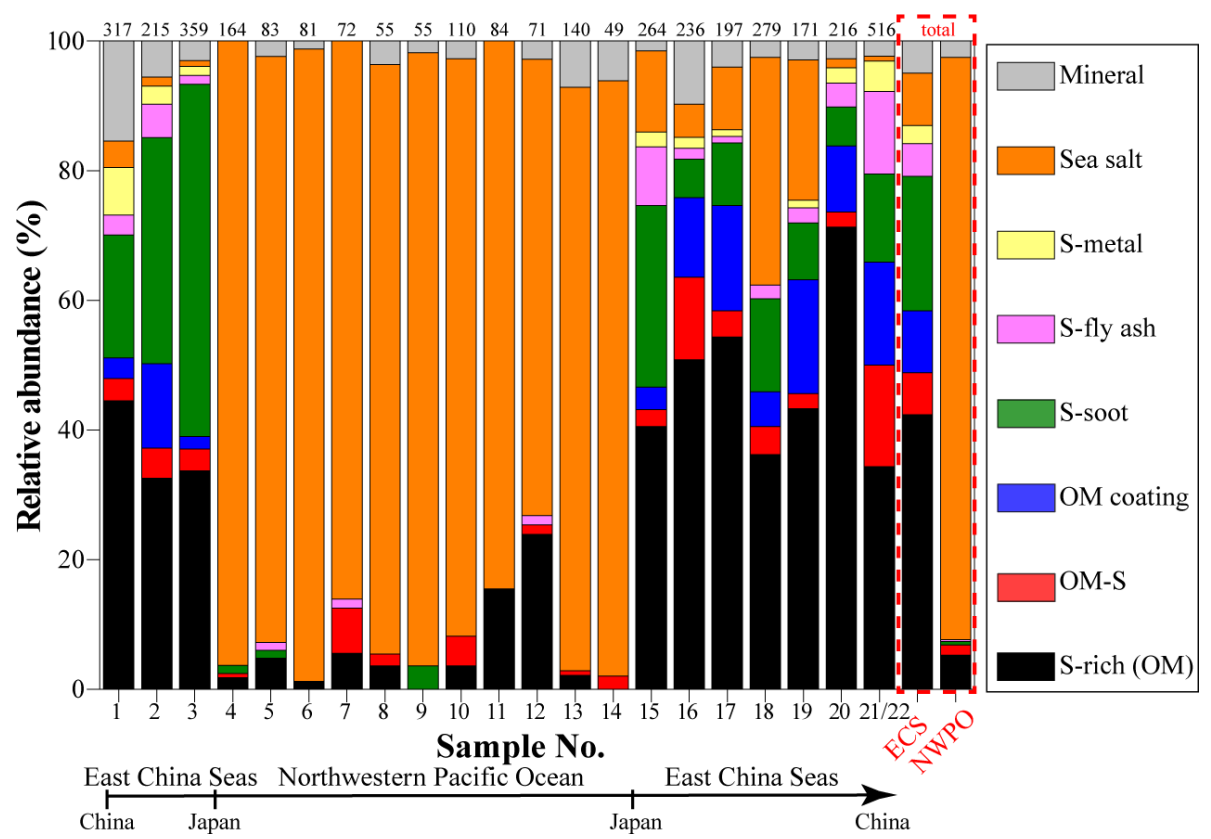

Figure 3. Relative abundances of eight types of aerosol particles in different samples. The number of analyzed aerosol particles is shown above the column.

\subsection{Aging of sea salt aerosols}

As the dominant aerosol particles in marine air, SSA particles accounted for $70 \%-98 \%$ in the NWPO. SSA could serve as reactive surfaces for heterogeneous and multiphase chemical reactions in the atmosphere, and these reactions could also alter the morphology and composition of SSA (Athanasopoulou et al., 2008; Chi et al., 2015; Laskin et al., 2012). Based on the morphology and composition of SSA, we further classified SSA into three categories: fresh SSA, partially aged SSA, and fully aged SSA (Fig. 5).
The fresh SSA did not experience any chemical modification in the atmosphere. TEM images of fresh SSA indicate the cubic $\mathrm{NaCl}$ core and coating composed of $\mathrm{MgCl}_{2}$ and $\mathrm{CaSO}_{4}$ (Fig. 5a). The $\mathrm{NaCl}$ core only contains $\mathrm{Na}$ and $\mathrm{Cl}$, with the atomic ratio of $\mathrm{Na}$ to $\mathrm{Cl}$ close to $1: 1$ (Fig. $5 \mathrm{~d}$ ). The major components in the coating are $\mathrm{Mg}, \mathrm{O}, \mathrm{S}, \mathrm{Cl}$, and $\mathrm{Ca}$ (Fig. 5e); thus, we infer their molecular forms as $\mathrm{MgCl}_{2}$ and $\mathrm{CaSO}_{4}$ (Geng et al., 2010; Chi et al., 2015; Pósfai et al., 1994; Buseck and Pósfai, 1999).

The partially aged SSA represents those SSA particles that undergo chemical modification but still retain part of the 
(a) Eastern China seas

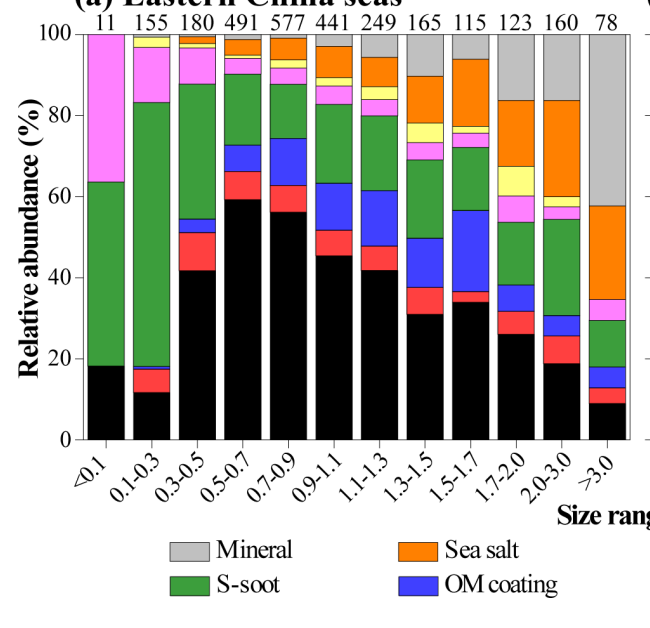

(b) Northwestern Pacific Ocean

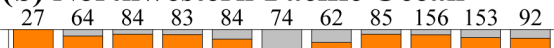

Figure 4. Relative abundances of individual particles in different size bins.

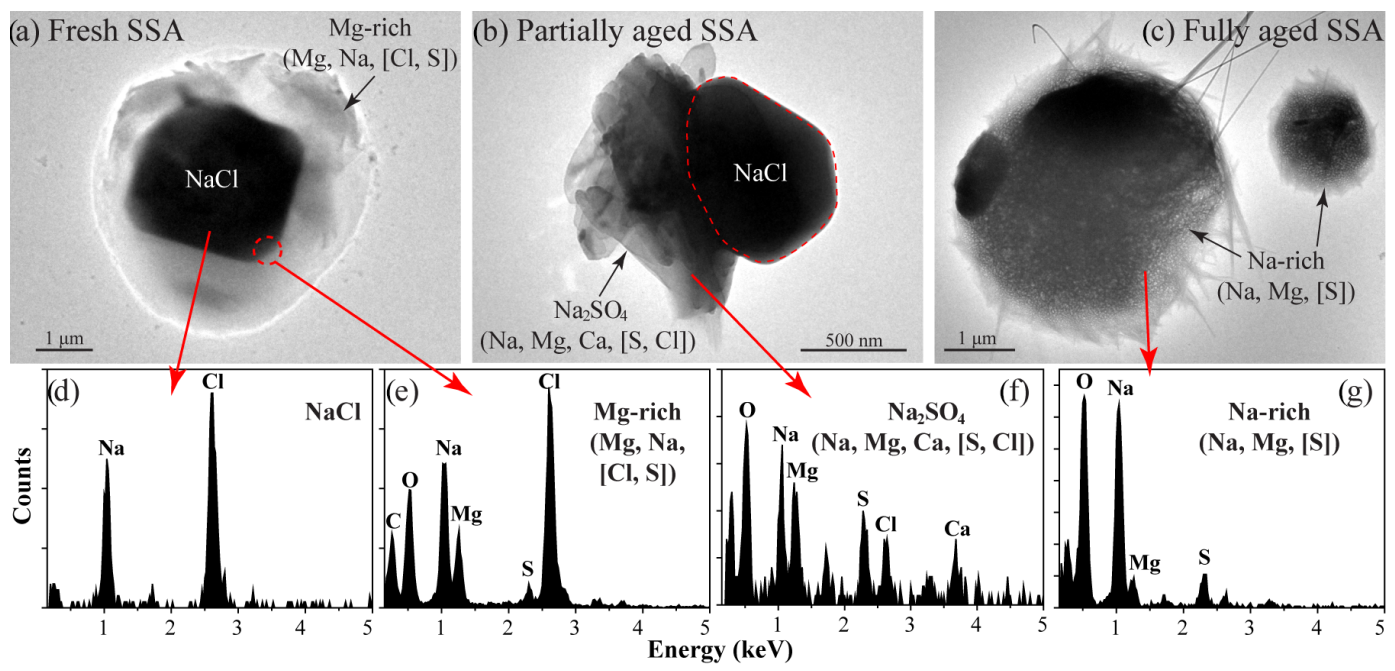

Figure 5. Morphology and EDS spectra of the typical fresh, partially aged, and fully aged SSA. The main anionic elements are shown in the square brackets.

$\mathrm{NaCl}$ core (Fig. 5b). The morphological differences can be observed between the fresh SSA and partially aged SSA. The $\mathrm{NaCl}$ core still persists in the partially aged SSA but cannot keep its regular cubic shape. Meanwhile, the coating composition turns into $\mathrm{O}, \mathrm{Na}, \mathrm{Mg}, \mathrm{Ca}$, and $\mathrm{S}$, with decreasing $\mathrm{Cl}$ (Fig. 5f). The SSA aging is attributed to the $\mathrm{Cl}$ depletion phenomena, which can be expressed as follows (Laskin et al., 2012):

$\mathrm{NaCl}(\mathrm{aq})+\mathrm{HA}(\mathrm{aq}, \mathrm{g}) \rightarrow \mathrm{NaA}(\mathrm{aq})+\mathrm{HCl}(\mathrm{aq}, \mathrm{g})$,

where $\mathrm{HA}$ represents atmospheric acids (e.g., $\mathrm{H}_{2} \mathrm{SO}_{4}$, $\mathrm{HNO}_{3}$, and methanesulfonic acid). $\mathrm{NaCl}$ in the $\mathrm{SSA}$ could react with inorganic (e.g., $\mathrm{HNO}_{3}$ and $\mathrm{H}_{2} \mathrm{SO}_{4}$ ) or organic acid (e.g., methanesulfonic acid), releasing volatile $\mathrm{HCl}$ (g) into the atmosphere, leading to depletion in chloride and enrichment in corresponding sodium salts.
We define the fully aged SSA as particles whose $\mathrm{NaCl}$ cores have been completely transformed into $\mathrm{NaNO}_{3}$ and $\mathrm{Na}_{2} \mathrm{SO}_{4}$. Figure $5 \mathrm{c}$ shows that the $\mathrm{NaCl}$ cores in the fully aged SSA entirely disappeared, leaving a rounder shape. The $\mathrm{Cl}$ element was no longer detected in the fully aged SSA, and the major aerosol components were the mixture of $\mathrm{NaNO}_{3}$ and $\mathrm{Na}_{2} \mathrm{SO}_{4}$ (Fig. $5 \mathrm{~g}$ ).

To evaluate composition differences of SSA, we present triangular diagrams of the $\mathrm{Na}-\mathrm{Cl}-\mathrm{S}$ weight ratio based on the EDS. Figure 6a shows that the fresh SSA is around the $\mathrm{NaCl}$, the partially aged SSA is distributed in the center of the triangle, and the fully aged SSA is around $\mathrm{NaNO}_{3}$ and $\mathrm{Na}_{2} \mathrm{SO}_{4}$. Figure $6 \mathrm{~b}$ shows that there were large variations of the SSA components in the ECS and NWPO. Our results show that most of the aged SSA in the ECS was the mixture of $\mathrm{NaNO}_{3}$ and $\mathrm{Na}_{2} \mathrm{SO}_{4}$, suggesting that $\mathrm{SSA}$ in the ECS 
underwent heterogeneous reactions and became fully aged SSA. SSA in the NWPO is widely distributed between $\mathrm{NaCl}$ and $\mathrm{NaNO}_{3} / \mathrm{Na}_{2} \mathrm{SO}_{4}$ in the triangular diagram, suggesting that these were partially aged SSA particles.

Figure 7 shows the relative abundance of SSA at different sampling sites from the ECS to the NWPO. In the ECS, $87 \%$ of SSA particles were fully aged. As the ship traveled into the NWPO, fully aged SSA particles decreased to $29 \%$; meanwhile, the proportion of fresh SSA increased to $57 \%$. The size distribution of SSA particles shows that the proportion of fresh SSA increased with the increase in particle size from 0.05 to $5 \mu \mathrm{m}$ (Fig. 8). In contrast, the proportion of fully aged SSA decreased with the increase in particle size from 0.05 to $5 \mu \mathrm{m}$. Overall, partially and fully aged SSA accounted for $61 \%$ of SSA particles smaller than $3 \mu \mathrm{m}$, while fresh SSA dominated ( $81 \%$ ) in SSA particles larger than $3 \mu \mathrm{m}$. Figure 8 also reveals that $94 \%$ of the fully aged SSA particles were smaller than $3 \mu \mathrm{m}$.

\section{Discussion}

Abundant BC, metal, and fly ash particles in the ECS show that long-range transport of anthropogenic aerosol particles from the polluted continental air constantly influences the ECS air during the spring and winter. Moreover, the existence of OM coating particles (10\%, Fig. 3) in the ECS indicates that secondary sulfate/nitrate particles underwent an aging process and formed the OM coating during their transport (Li et al., 2021). This result suggests that the long-range transported air masses from continental areas brought abundant anthropogenic gases such as $\mathrm{NO}_{x}, \mathrm{SO}_{2}$, and VOCs into marine air. Indeed, the HYSPLIT backward trajectories show that the air masses in the ECS samples were mainly from eastern China (Fig. 1). Under the influence of the westerlies, a large number of anthropogenic and natural pollutants are transported to the ECS and further influence its air quality. Most of the air masses in the NWPO samples originated from the northwest, passing through Japan to sampling locations within $48 \mathrm{~h}$.

Figure 3 shows that anthropogenic aerosols were relatively low in the NWPO (8\%), suggesting a slight influence from continental aerosols. However, we observed severe $\mathrm{Cl}$ depletion in SSA in some samples in the NWPO. The Cl depletion of SSA is mainly caused by the heterogeneous reactions with acidic gaseous pollutants in marine air (Hsu et al., 2007; Chi et al., 2015; Laskin et al., 2012). By comparing the aging degree of SSA and air mass backward trajectories, we found that the air masses with a relatively high proportion of fully aged SSA particles (nos. 13 and 15) mostly formed due to the anthropogenic gaseous pollutants (e.g., $\mathrm{SO}_{2}$ and $\mathrm{NO}_{x}$ ) from China and Japan (Fig. S1). The result suggests that aerosol particles and gases might have different transport distances. Aerosol particles could be significantly removed by dry or wet deposition. However, the anthropogenic gases can be transported further to the NWPO air. Over the western Pacific, Koike et al. (2003) also found that anthropogenic gaseous pollutants (e.g., $\mathrm{NO}_{x}$ and $\mathrm{SO}_{2}$ ) from East Asia have higher transport efficiency than aerosols from the same region. Meanwhile, the surface changes in SSA can be considered a potential indicator for anthropogenic gaseous pollutants in remote marine air.

Based on the results and discussion above, a conceptual model was proposed to summarize the impact of long-range transported anthropogenic air pollutants on marine aerosols (Fig. 9). Both anthropogenic gases and aerosol particles could be transported to the downwind marine air. Anthropogenic aerosol particles from the continent significantly influence the ECS air. During the transport, aerosol particles could be scavenged due to dry or wet deposition, while some reactive gases can be transported further to the NWPO air and influence the aging of SSA particles.

Figure 6 shows a higher percentage of $\mathrm{Cl}$-free SSA particles (on the $\mathrm{Cl}=0$ line) in the ECS than those in the NWPO, suggesting that modifications of SSA in the ECS were much more severe than those in the NWPO. Referring to Zhang et al. (2003), we further provide the dash line that $\mathrm{Na}: \mathrm{Cl}: \mathrm{S}$ was changed only by reaction with $\mathrm{H}_{2} \mathrm{SO}_{4}$. Thus, particles above the dash line show that $\mathrm{Cl}$ in these SSA particles was not only replaced by $\mathrm{S}$ deposition, but that other chemical processes (e.g., reactions with $\mathrm{HNO}_{3}$ and organic acids) also contributed to the $\mathrm{Cl}$ depletion. The number of fully aged SSA particles above the dash line was further counted. For the fully aged SSA particles, $70 \%$ of them in the ECS were above the dash line, while the proportion increased to $86 \%$ in the NWPO (Fig. 6). The result indicates that S deposition could not compensate for $\mathrm{Cl}$ depletion in most of the fully aged SSA particles in both the ECS and NWPO. There must be other acids leading to $\mathrm{Cl}$ depletion in the fully aged SSA particles besides the reaction with $\mathrm{H}_{2} \mathrm{SO}_{4}$.

It is well known that organic acids could also be a reason for $\mathrm{Cl}$ depletion in SSA (Laskin et al., 2012; Chi et al., 2015; Ghorai et al., 2014). The oxidation of dimethyl sulfide (DMS) emitted from phytoplankton contributes to the $\mathrm{Cl}$ depletion in SSA (Sievering et al., 2004). Both anthropogenic acidic gases and DMS in the ECS were found to be higher than that in the NWPO (Figs. S1 and S2). Compared with the ECS, we found that DMS in our NWPO shipping area had lower mass concentrations and minor fluctuations (3-6 $\times 10^{-11} \mathrm{~kg} \mathrm{~m}^{-3}$, Fig. S2). However, the percentages of aged SSA differed widely (from $23 \%$ to $88 \%$ ) within the NWPO. We deduce that the low concentration of the DMS only slightly modified part of SSA in the NWPO, but it was not enough to influence all the SSA. Moreover, Zhu et al. (2019) reported that secondary sulfate particles in the NWPO mostly came from the long-range transported acidic gases during the sampling period. The contribution of DMS to non-sea-salt sulfate is less than $6 \%$ in the remote ocean of the Northern Hemisphere (Quinn et al., 1990; Savoie et al., 1994; George et al., 2008). Therefore, a large proportion of 

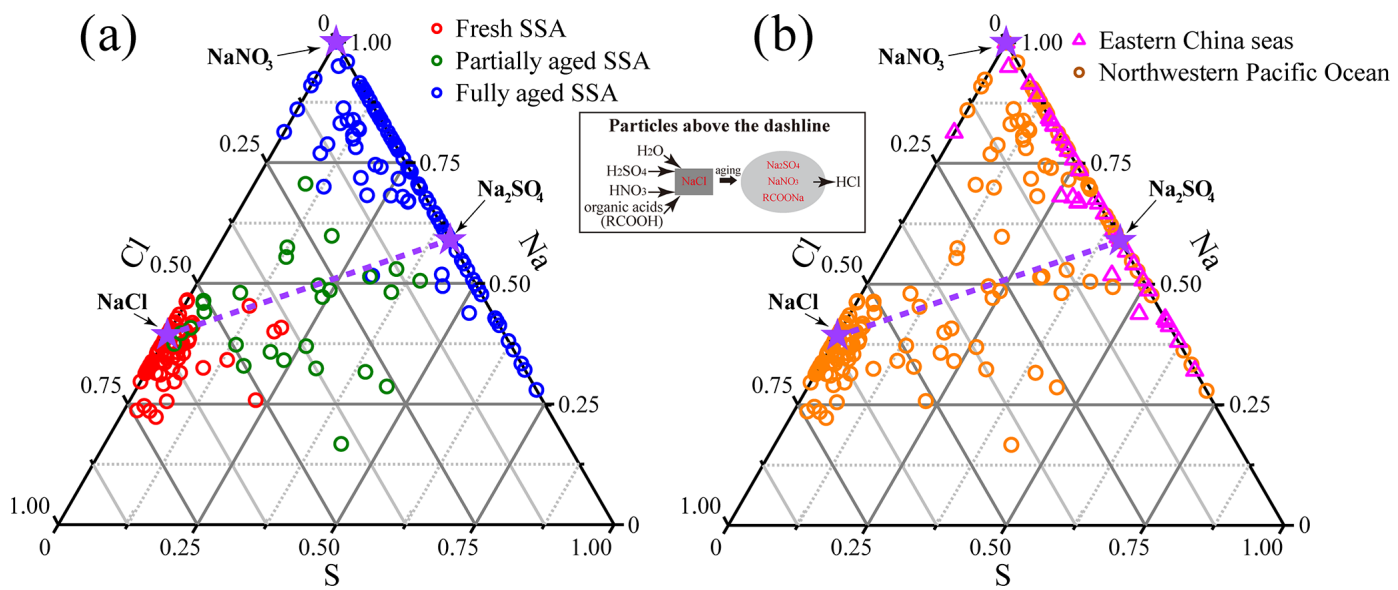

Figure 6. Triangular diagram of Na-Cl-S from EDS data (weight percentage) showing the elemental composition of SSA particles. The three stars represent pure $\mathrm{NaCl}, \mathrm{Na}_{2} \mathrm{SO}_{4}$, and $\mathrm{NaNO}_{3}$, respectively. The dash line indicates that $\mathrm{Na}: \mathrm{Cl}: \mathrm{S}$ is changed only by the postulated reaction of $2 \mathrm{NaCl}+\mathrm{H}_{2} \mathrm{SO}_{4} \rightarrow \mathrm{Na}_{2} \mathrm{SO}_{4}+2 \mathrm{HCl}(\mathrm{g}$ ) (Zhang et al., 2003). Particles above the dash line are those where $\mathrm{S}$ cannot compensate $\mathrm{Cl}$ losses, and there should be other processes causing $\mathrm{Cl}$ depletion.

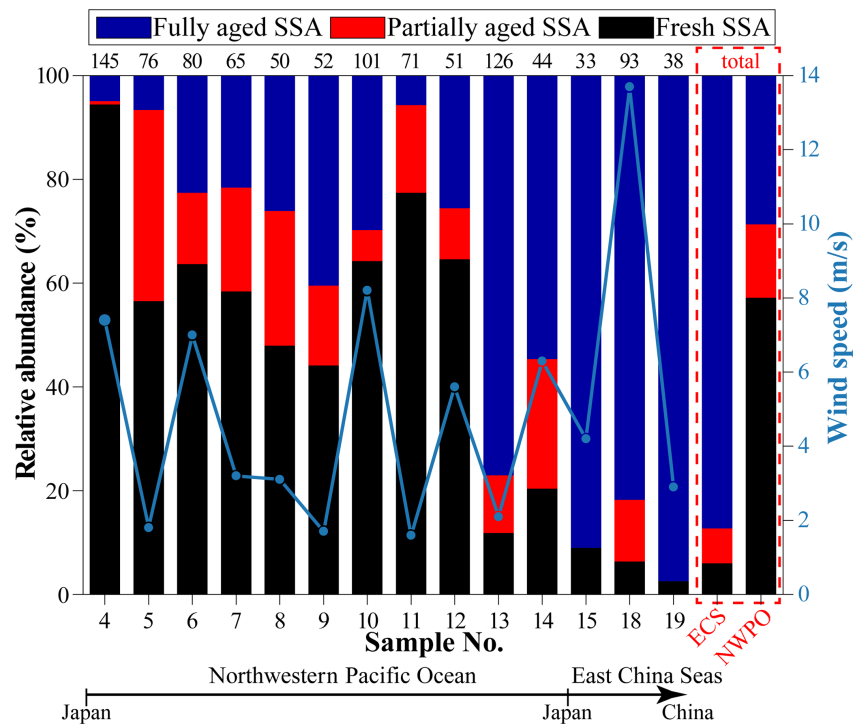

Figure 7. Relative abundances of the fresh, partially aged, and fully aged SSA particles in different samples. Samples with SSA particles less than 30 are excluded due to the small number. The line indicates the wind speed of the corresponding sample.

aged SSA particles in the NWPO should be mainly attributed to the anthropogenic acidic gases from long-range transport.

Meteorological conditions also play an important role in SSA particle aging. The hygroscopic cycle of the pure SSA particles shows the deliquescence relative humidity (DRH) near $75 \%$ and its efflorescence relative humidity (ERH) near $44 \%$. However, the natural SSA particles begin to take up water at $57 \%$ and form a liquid layer on particles due to various inorganic compounds (e.g., $\mathrm{MgSO}_{4}, \mathrm{MgCl}_{2}$, and $\mathrm{CaCl}_{2}$ ) (Wise et al., 2009). In our study, the sampling RH values

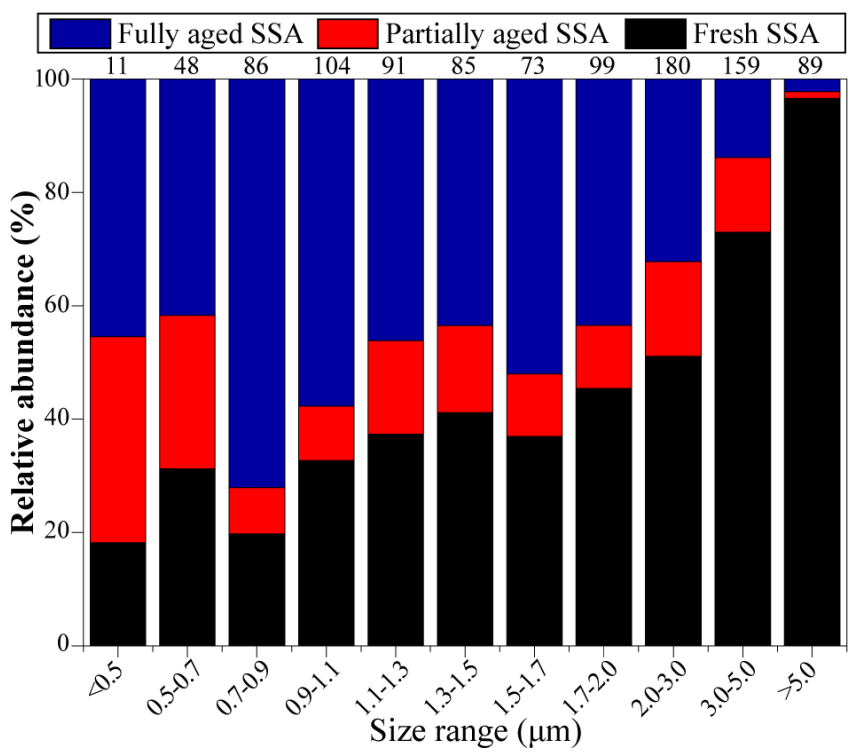

Figure 8. Relative abundances of three types of SSA particles in different size bins.

were higher than $40 \%$, and more than half of them were collected at RH above $60 \%$ (Table S1). Therefore, most SSA particles should exist as aqueous droplets during the particle hygroscopic cycle, or at least particle surfaces kept the aqueous phase due to the existence of various inorganic compounds (Wise et al., 2009). One previous study showed that $\mathrm{Cl}$ depletion in the aqueous SSA particles due to ozone under UV can produce $\mathrm{Cl}_{2}$ (Oum et al., 1998). However, the averaged ozone concentration ranging from 42 to $50 \mathrm{ppb}$ during our cruise did not exhibit large differences from the satellite observation in marine air (Fig. S1c). Therefore, we conclude that ozone might be one factor causing $\mathrm{Cl}$ depletion in aque- 


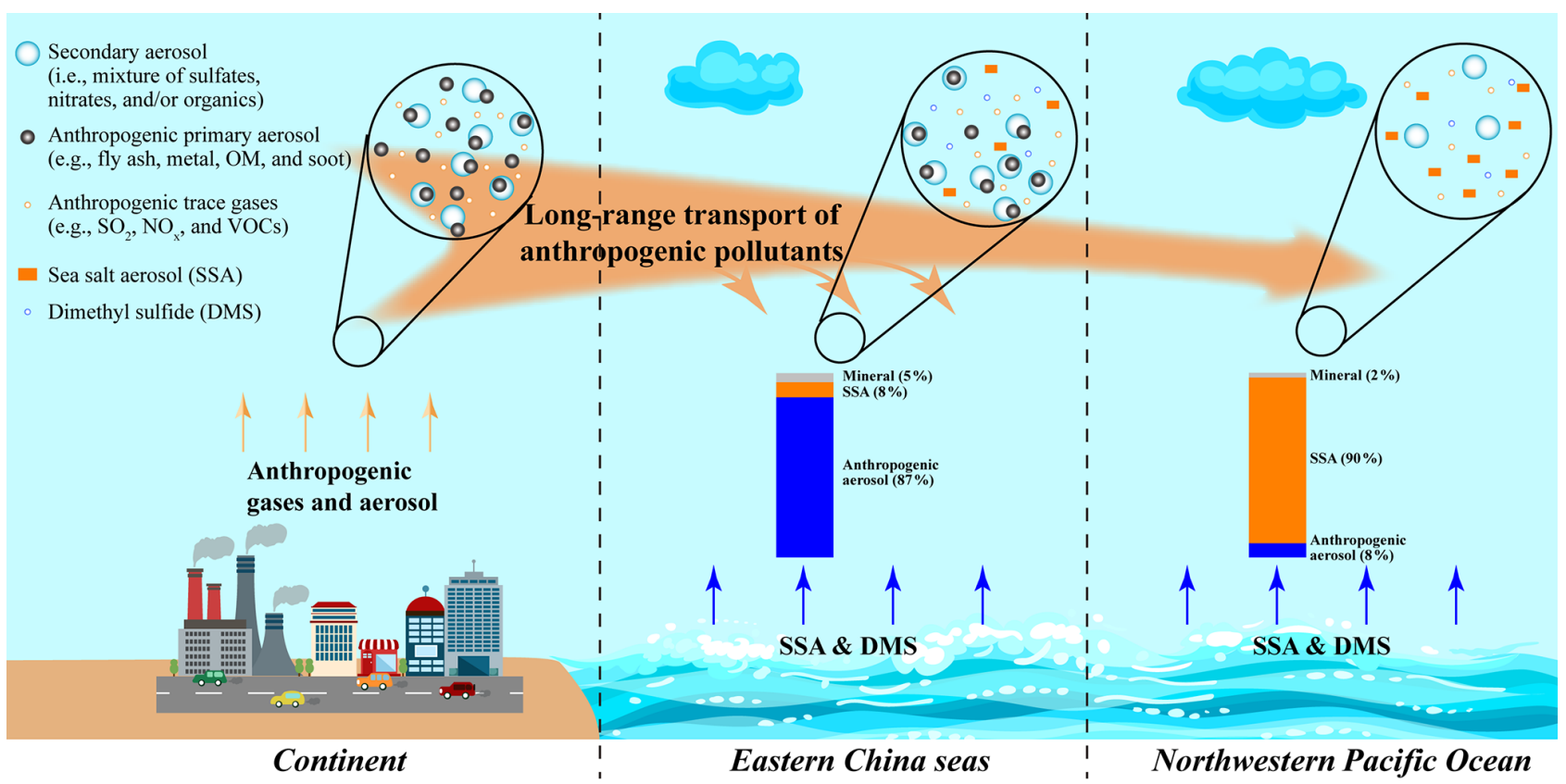

Figure 9. Schematic diagram showing the impact of long-range transported anthropogenic air pollutants on marine aerosols.

ous SSA particles but should not be the major reason leading to the variations of SSA aging degree in different NWPO samples.

Previous studies found that SSA emissions increased with the increase in wind speed (Shinozuka et al., 2004; Pant et al., 2008; Feng et al., 2017). In our study, the proportion of fresh SSA increases with increasing wind speed (Fig. 7), consistent with the aforementioned studies. An SSA particle with a smaller size has lower dry deposition velocity and a longer lifetime in the air (Lewis and Schwartz, 2004), which could enhance the $\mathrm{Cl}$ depletion due to inorganic or organic acids. This could be the reason that partially and fully aged SSA particles were mostly in the smaller size range $(<3 \mu \mathrm{m})$ (Fig. 8). By contrast, the newly emitted coarse SSA particles with high dry deposition velocity are more likely to deposit to the ocean, resulting in less reacted SSA. As a result, the fresh SSA from local sea spray was mostly found in the coarse size range (larger than $3 \mu \mathrm{m}$ ) in our samples (Fig. 8). This result suggests that it is crucial to study aging process among the size-resolved SSA, especially particles smaller than $3 \mu \mathrm{m}$.

In the future, we need to pay more attention to the influence of anthropogenic gaseous pollutants on the SSA aging in remote marine air. On the one hand, the aging processes could modify the hygroscopicity of SSA, determining their morphology and phase state in the humidified marine environment, in the end directly affecting optical properties of SSA (Wang et al., 2019). On the other hand, the hygroscopicity change due to SSA aging could alter CCN activity and indirectly affect global climate (Murphy et al., 1998; Pierce and Adams, 2006; Hu et al., 2005). Meanwhile, the SSA also serves as an important sink for the anthropogenic acidic gases in remote marine areas (Chi et al., 2015; Laskin et al., 2012). Thus, in future research, it would be crucial to quantify the anthropogenic acidic gases scavenged by SSA.

\section{Conclusions}

Individual aerosol particles were collected from 17 March to 22 April 2014 onboard the R/V Dongfanghong 2 from the ECS to the NWPO. We classified aerosol particles based on their composition, morphology, and mixing state: mineral, sea salt, S-metal, S-fly ash, S-soot, OM coating, OM-S, and S-rich. Microscopic analysis showed that anthropogenic aerosols accounted for $87 \%$ of the total particle number in the ECS. In particular, higher proportions of secondary particles (i.e., S-rich particles, $42 \%$, and OM coating particles, $10 \%)$ were found in the ECS. Meanwhile, anthropogenic aerosols are relatively low in the NWPO $(8 \%)$.

TEM observations revealed that SSA particles were the most abundant in the NWPO atmosphere, accounting for $90 \%$ of all analyzed aerosol particles. The $\mathrm{Cl}$ depletion of SSA particles caused by the heterogeneous reactions with acidic gaseous pollutants was further observed. Three types of SSA particles, fresh, partially aged, and fully aged, were classified. Fully aged SSA particles were the dominant SSA in the ECS (87\%), while fully aged SSA particles decreased to $29 \%$ in the NWPO. The severe aging of SSA (partially and fully aged, at most $88 \%$ of SSA) was still found in the NWPO, despite there being only minor anthropogenic aerosol particles. These results show that aerosol particles from the continent air might be removed by dry and wet de- 
position, but the air pollutants were transported further to the NWPO. The aging of SSA particles has important effects on their hygroscopic and optical properties, one effect being the promotion of heterogeneous reaction with acidic gases in the NWPO. Our observations show that more attention should be given to the influence of anthropogenic gaseous pollutants on the $\mathrm{Cl}$ depletion on SSA in remote marine air.

Data availability. All data presented in this paper are available upon request from the corresponding author (liweijun@zju.edu.cn).

Supplement. The supplement related to this article is available online at: https://doi.org/10.5194/acp-21-17715-2021-supplement.

Author contributions. LX and WL conceived the study and wrote the article. The sampling during the research cruise was organized by XL, HG, and XY. LX, WL, LL, JZ, YZ, YW, and QY carried out TEM analyses of individual particles. DZ and LB contributed to the improvement of this paper. All the authors reviewed and approved the paper.

Competing interests. The contact author has declared that neither they nor their co-authors have any competing interests.

Disclaimer. Publisher's note: Copernicus Publications remains neutral with regard to jurisdictional claims in published maps and institutional affiliations.

Acknowledgements. We thank Peter Hyde for his editorial comments. We acknowledge the NOAA Air Resources Laboratory for the provision of the HYSPLIT transport and dispersion model and READY website (http://www.ready.noaa.gov, last access: 30 November 2021) used in this publication.

Financial support. This research was supported by the National Natural Science Foundation of China (grant nos. 42075096, 91844301, and 41805099), the National Key R\&D Program of China (grant no. 2017YFC0212700), the Zhejiang Provincial Natural Science Foundation of China (grant no. LZ19D050001), and the China Postdoctoral Science Foundation (grant no. 2019M662021).

Review statement. This paper was edited by Alexander Laskin and reviewed by three anonymous referees.

\section{References}

Athanasopoulou, E., Tombrou, M., Pandis, S. N., and Russell, A. G.: The role of sea-salt emissions and heterogeneous chemistry in the air quality of polluted coastal areas, Atmos. Chem. Phys., 8, 5755-5769, https://doi.org/10.5194/acp-8-5755-2008, 2008.

Bondy, A. L., Wang, B., Laskin, A., Craig, R. L., Nhliziyo, M. V., Bertman, S. B., Pratt, K. A., Shepson, P. B., and Ault, A. P.: Inland Sea Spray Aerosol Transport and Incomplete Chloride Depletion: Varying Degrees of Reactive Processing Observed during SOAS, Environ. Sci. Technol., 51, 9533-9542, https://doi.org/10.1021/acs.est.7b02085, 2017.

Buseck, P. R. and Pósfai, M.: Airborne minerals and related aerosol particles: Effects on climate and the environment, P. Natl. Acad. Sci. USA, 96, 3372-3379, https://doi.org/10.1073/pnas.96.7.3372, 1999.

Chi, J. W., Li, W. J., Zhang, D. Z., Zhang, J. C., Lin, Y. T., Shen, X. J., Sun, J. Y., Chen, J. M., Zhang, X. Y., Zhang, Y. M., and Wang, W. X.: Sea salt aerosols as a reactive surface for inorganic and organic acidic gases in the Arctic troposphere, Atmos. Chem. Phys., 15, 11341-11353, https://doi.org/10.5194/acp-15-113412015, 2015.

Cravigan, L. T., Mallet, M. D., Vaattovaara, P., Harvey, M. J., Law, C. S., Modini, R. L., Russell, L. M., Stelcer, E., Cohen, D. D., Olsen, G., Safi, K., Burrell, T. J., and Ristovski, Z.: Sea spray aerosol organic enrichment, water uptake and surface tension effects, Atmos. Chem. Phys., 20, 7955-7977, https://doi.org/10.5194/acp-20-7955-2020, 2020.

Feng, J. L., Guo, Z. G., Zhang, T. R., Yao, X. H., Chan, C. K., and Fang, M.: Source and formation of secondary particulate matter in $\mathrm{PM}_{2.5}$ in Asian continental outflow, J. Geophys. Res.-Atmos., 117, D03302, https://doi.org/10.1029/2011jd016400, 2012.

Feng, L., Shen, H., Zhu, Y., Gao, H., and Yao, X.: Insight into Generation and Evolution of Sea-Salt Aerosols from Field Measurements in Diversified Marine and Coastal Atmospheres, Sci. Rep., 7, 41260, https://doi.org/10.1038/srep41260, 2017.

Fu, J., Wang, B., Chen, Y., and Ma, Q.: The influence of continental air masses on the aerosols and nutrients deposition over the western North Pacific, Atmos. Environ., 172, 1-11, https://doi.org/10.1016/j.atmosenv.2017.10.041, 2018.

Geng, H., Ryu, J., Jung, H.-J., Chung, H., Ahn, K.-H., and Ro, C.-U.: Single-Particle Characterization of Summertime Arctic Aerosols Collected at Ny-Ålesund, Svalbard, Environ. Sci. Technol., 44, 2348-2353, https://doi.org/10.1021/es903268j, 2010.

George, S. K., Nair, P. R., Parameswaran, K., Jacob, S., and Abraham, A.: Seasonal trends in chemical composition of aerosols at a tropical coastal site of India, J. Geophys. Res.-Atmos., 113, D16209, https://doi.org/10.1029/2007JD009507, 2008.

Ghorai, S., Wang, B., Tivanski, A., and Laskin, A.: Hygroscopic Properties of Internally Mixed Particles Composed of $\mathrm{NaCl}$ and Water-Soluble Organic Acids, Environ. Sci. Technol., 48, 2234 2241, https://doi.org/10.1021/es404727u, 2014.

Guo, L., Chen, Y., Wang, F., Meng, X., Xu, Z., and Zhuang, G.: Effects of Asian dust on the atmospheric input of trace elements to the East China Sea, Mar. Chem., 163, 19-27, https://doi.org/10.1016/j.marchem.2014.04.003, 2014.

Hsu, S.-C., Liu, S. C., Kao, S.-J., Jeng, W.-L., Huang, Y.-T., Tseng, C.-M., Tsai, F., Tu, J.-Y., and Yang, Y.: Water-soluble species in the marine aerosol from the northern South China Sea: High chloride depletion related to air pollution, J. Geophys. Res.Atmos., 112, D19304, https://doi.org/10.1029/2007JD008844, 2007. 
Hu, R. M., Blanchet, J. P., and Girard, E.: Evaluation of the direct and indirect radiative and climate effects of aerosols over the western Arctic, J. Geophys. Res.-Atmos., 110, D11213, https://doi.org/10.1029/2004JD005043, 2005.

Kang, M., Fu, P., Kawamura, K., Yang, F., Zhang, H., Zang, Z., Ren, H., Ren, L., Zhao, Y., Sun, Y., and Wang, Z.: Characterization of biogenic primary and secondary organic aerosols in the marine atmosphere over the East China Sea, Atmos. Chem. Phys., 18, 13947-13967, https://doi.org/10.5194/acp-18-139472018, 2018.

Kanji, Z. A., Ladino, L. A., Wex, H., Boose, Y., BurkertKohn, M., Cziczo, D. J., and Krämer, M.: Overview of Ice Nucleating Particles, Meteor. Mon., 58, 1.1-1.33, https://doi.org/10.1175/amsmonographs-d-16-0006.1, 2017.

Koike, M., Kondo, Y., Kita, K., Takegawa, N., Masui, Y., Miyazaki, Y., Ko, M. W., Weinheimer, A. J., Flocke, F., Weber, R. J., Thornton, D. C., Sachse, G. W., Vay, S. A., Blake, D. R., Streets, D. G., Eisele, F. L., Sandholm, S. T., Singh, H. B., and Talbot, R. W.: Export of anthropogenic reactive nitrogen and sulfur compounds from the East Asia region in spring, J. Geophys. Res.-Atmos., 108, 8789, https://doi.org/10.1029/2002JD003284, 2003.

Kondo, Y., Moteki, N., Oshima, N., Ohata, S., Koike, M., Shibano, Y., Takegawa, N., and Kita, K.: Effects of wet deposition on the abundance and size distribution of black carbon in East Asia, J. Geophys. Res.-Atmos., 121, 4691-4712, https://doi.org/10.1002/2015JD024479, 2016.

Kong, X., Wolf, M. J., Roesch, M., Thomson, E. S., Bartels-Rausch, T., Alpert, P. A., Ammann, M., Prisle, N. L., and Cziczo, D. J.: A continuous flow diffusion chamber study of sea salt particles acting as cloud nuclei: deliquescence and ice nucleation, Tellus B, 70, 1-11, https://doi.org/10.1080/16000889.2018.1463806, 2018.

Laskin, A., Moffet, R. C., Gilles, M. K., Fast, J. D., Zaveri, R. A., Wang, B., Nigge, P., and Shutthanandan, J.: Tropospheric chemistry of internally mixed sea salt and organic particles: Surprising reactivity of $\mathrm{NaCl}$ with weak organic acids, J. Geophys. Res.Atmos., 117, D15302, https://doi.org/10.1029/2012JD017743, 2012.

Lewis, E. R. and Schwartz, S. E.: Sea salt aerosol production: mechanisms, methods, measurements, and models, American Geophysical Union, Washington, DC, USA, 2004.

Li, W., Shao, L., Shi, Z., Chen, J., Yang, L., Yuan, Q., Yan, C., Zhang, X., Wang, Y., Sun, J., Zhang, Y., Shen, X., Wang, Z., and Wang, W.: Mixing state and hygroscopicity of dust and haze particles before leaving Asian continent, J. Geophys. Res.-Atmos., 119, 1044-1059, https://doi.org/10.1002/2013JD021003, 2014.

Li, W., Shao, L., Zhang, D., Ro, C.-U., Hu, M., Bi, X., Geng, H., Matsuki, A., Niu, H., and Chen, J.: A review of single aerosol particle studies in the atmosphere of East Asia: morphology, mixing state, source, and heterogeneous reactions, J. Clean. Prod., 112, 1330-1349, https://doi.org/10.1016/j.jclepro.2015.04.050, 2016a.

Li, W., Sun, J., Xu, L., Shi, Z., Riemer, N., Sun, Y., Fu, P., Zhang, J., Lin, Y., Wang, X., Shao, L., Chen, J., Zhang, X., Wang, Z., and Wang, W.: A conceptual framework for mixing structures in individual aerosol particles, J. Geophys. Res.-Atmos., 121, 1378413798, https://doi.org/10.1002/2016JD025252, 2016b.

Li, W., Xu, L., Liu, X., Zhang, J., Lin, Y., Yao, X., Gao, H., Zhang, D., Chen, J., Wang, W., Harrison, R. M., Zhang, X., Shao, L.,
Fu, P., Nenes, A., and Shi, Z.: Air pollution-aerosol interactions produce more bioavailable iron for ocean ecosystems, Sci. Adv., 3, e1601749, https://doi.org/10.1126/sciadv.1601749, 2017.

Li, W., Liu, L., Zhang, J., Xu, L., Wang, Y., Sun, Y., and Shi, Z.: Microscopic Evidence for Phase Separation of Organic Species and Inorganic Salts in Fine Ambient Aerosol Particles, Environ. Sci. Technol., 55, 2234-2242, https://doi.org/10.1021/acs.est.0c02333, 2021.

Luo, L., Yao, X. H., Gao, H. W., Hsu, S. C., Li, J. W., and Kao, S. J.: Nitrogen speciation in various types of aerosols in spring over the northwestern Pacific Ocean, Atmos. Chem. Phys., 16, 325-341, https://doi.org/10.5194/acp-16-325-2016, 2016.

Mahowald, N. M., Hamilton, D. S., Mackey, K. R. M., Moore, J. K., Baker, A. R., Scanza, R. A., and Zhang, Y.: Aerosol trace metal leaching and impacts on marine microorganisms, Nat. Commun., 9, 2614, https://doi.org/10.1038/s41467-018-04970-7, 2018.

McInnes, L. M., Covert, D. S., Quinn, P. K., and Germani, M. S.: Measurements of chloride depletion and sulfur enrichment in individual sea-salt particles collected from the remote marine boundary layer, J. Geophys. Res.-Atmos., 99, 8257-8268, https://doi.org/10.1029/93JD03453, 1994.

Moffet, R. C., Furutani, H., Rödel, T. C., Henn, T. R., Sprau, P. O., Laskin, A., Uematsu, M., and Gilles, M. K.: Iron speciation and mixing in single aerosol particles from the Asian continental outflow, J. Geophys. Res.-Atmos., 117, D07204, https://doi.org/10.1029/2011JD016746, 2012.

Mouri, H. and Okada, K.: Shattering and modification of sea-salt particles in the marine atmosphere, Geophys. Res. Lett., 20, 4952, https://doi.org/10.1029/92GL03004, 1993.

Murphy, D., Anderson, J., Quinn, P., McInnes, L., Brechtel, F., Kreidenweis, S., Middlebrook, A., Pósfai, M., Thomson, D., and Buseck, P.: Influence of sea-salt on aerosol radiative properties in the Southern Ocean marine boundary layer, Nature, 392, 62-65, https://doi.org/10.1038/32138, 1998.

O'Dowd Colin, D. and de Leeuw, G.: Marine aerosol production: a review of the current knowledge, Philos. T. Roy. Soc. A., 365, 1753-1774, https://doi.org/10.1098/rsta.2007.2043, 2007.

Oum, K. W., Lakin, M. J., DeHaan, D. O., Brauers, T., and Finlayson-Pitts, B. J.: Formation of Molecular Chlorine from the Photolysis of Ozone and Aqueous Sea-Salt Particles, Science, 279, 74-76, https://doi.org/10.1126/science.279.5347.74, 1998.

Pósfai, M., Anderson, J. R., Buseck, P. R., Shattuck, T. W., and Tindale, N. W.: Constituents of a remote pacific marine aerosol: A tem study, Atmos. Environ., 28, 1747-1756, https://doi.org/10.1016/1352-2310(94)90137-6, 1994.

Pant, V., Deshpande, C. G., and Kamra, A. K.: On the aerosol number concentration-wind speed relationship during a severe cyclonic storm over south Indian Ocean, J. Geophys. Res.-Atmos., 113, D02206, https://doi.org/10.1029/2006JD008035, 2008.

Pierce, J. R. and Adams, P. J.: Global evaluation of CCN formation by direct emission of sea salt and growth of ultrafine sea salt, J. Geophys. Res.-Atmos., 111, D06203, https://doi.org/10.1029/2005JD006186, 2006.

Quinn, P. K., Bates, T. S., Johnson, J. E., Covert, D. S., and Charlson, R. J.: Interactions between the sulfur and reduced nitrogen cycles over the central Pacific Ocean, J. Geophys. Res.-Atmos., 95, 16405-16416, https://doi.org/10.1029/JD095iD10p16405, 1990. 
Riemer, N., Ault, A. P., West, M., Craig, R. L., and Curtis, J. H.: Aerosol Mixing State: Measurements, Modeling, and Impacts, Rev. Geophys., 57, 187-249, https://doi.org/10.1029/2018rg000615, 2019.

Savoie, D. L., Prospero, J. M., Arimoto, R., and Duce, R. A.: Non-sea-salt sulfate and methanesulfonate at American Samoa, J. Geophys. Res.-Atmos., 99, 3587-3596, https://doi.org/10.1029/93JD03337, 1994.

Shi, J., Wang, N., Gao, H., Baker, A. R., Yao, X., and Zhang, D.: Phosphorus solubility in aerosol particles related to particle sources and atmospheric acidification in Asian continental outflow, Atmos. Chem. Phys., 19, 847-860, https://doi.org/10.5194/acp-19-847-2019, 2019.

Shi, Z., Krom, M. D., Jickells, T. D., Bonneville, S., Carslaw, K. S., Mihalopoulos, N., Baker, A. R., and Benning, L. G.: Impacts on iron solubility in the mineral dust by processes in the source region and the atmosphere: A review, Aeolian Res., 5, 21-42, https://doi.org/10.1016/j.aeolia.2012.03.001, 2012.

Shinozuka, Y., Clarke, A. D., Howell, S. G., Kapustin, V. N., and Huebert, B. J.: Sea-salt vertical profiles over the Southern and tropical Pacific oceans: Microphysics, optical properties, spatial variability, and variations with wind speed, J. Geophys. Res.Atmos., 109, D24201, https://doi.org/10.1029/2004JD004975, 2004.

Sievering, H., Cainey, J., Harvey, M., McGregor, J., Nichol, S., and Quinn, P.: Aerosol non-sea-salt sulfate in the remote marine boundary layer under clear-sky and normal cloudiness conditions: Ocean-derived biogenic alkalinity enhances sea-salt sulfate production by ozone oxidation, J. Geophys. Res.-Atmos., 109, D19317, https://doi.org/10.1029/2003JD004315, 2004.

Stein, A. F., Draxler, R. R., Rolph, G. D., Stunder, B. J. B., Cohen, M. D., and Ngan, F.: NOAA's HYSPLIT Atmospheric Transport and Dispersion Modeling System, B. Am. Meteorol. Soc., 96, 2059-2077, https://doi.org/10.1175/bams-d-14-00110.1, 2015.

Ueda, S., Osada, K., Hara, K., Yabuki, M., Hashihama, F., and Kanda, J.: Morphological features and mixing states of sootcontaining particles in the marine boundary layer over the Indian and Southern oceans, Atmos. Chem. Phys., 18, 9207-9224, https://doi.org/10.5194/acp-18-9207-2018, 2018.

Uematsu, M., Hattori, H., Nakamura, T., Narita, Y., Jung, J., Matsumoto, K., Nakaguchi, Y., and Kumar, M. D.: Atmospheric transport and deposition of anthropogenic substances from the Asia to the East China Sea, Mar. Chem., 120, 108-115, https://doi.org/10.1016/j.marchem.2010.01.004, 2010.
Uno, I., Eguchi, K., Yumimoto, K., Takemura, T., Shimizu, A., Uematsu, M., Liu, Z., Wang, Z., Hara, Y., and Sugimoto, N.: Asian dust transported one full circuit around the globe, Nat. Geosci., 2, 557-560, https://doi.org/10.1038/ngeo583, 2009.

Wang, J., Ye, J., Zhang, Q., Zhao, J., Wu, Y., Li, J., Liu, D., Li, W., Zhang, Y., Wu, C., Xie, C., Qin, Y., Lei, Y., Huang, X., Guo, J., Liu, P., Fu, P., Li, Y., Lee, H. C., Choi, H., Zhang, J., Liao, H., Chen, M., Sun, Y., Ge, X., Martin, S. T., and Jacob, D. J.: Aqueous production of secondary organic aerosol from fossil-fuel emissions in winter Beijing haze, P. Natl. Acad. Sci. USA., 118, e2022179118, https://doi.org/10.1073/pnas.2022179118, 2021.

Wang, Z., Bi, L., Yi, B., and Zhang, X.: How the Inhomogeneity of Wet Sea Salt Aerosols Affects Direct Radiative Forcing, Geophys. Res. Lett., 46, 1805-1813, https://doi.org/10.1029/2018GL081193, 2019.

Wise, M. E., Freney, E. J., Tyree, C. A., Allen, J. O., Martin, S. T., Russell, L. M., and Buseck, P. R.: Hygroscopic behavior and liquid-layer composition of aerosol particles generated from natural and artificial seawater, J. Geophys. Res.-Atmos., 114, D03201, https://doi.org/10.1029/2008JD010449, 2009.

Yao, X. and Zhang, L.: Chemical processes in seasalt chloride depletion observed at a Canadian rural coastal site, Atmos. Environ., 46, 189-194, https://doi.org/10.1016/j.atmosenv.2011.09.081, 2012.

Zhang, D., Iwasaka, Y., Shi, G., Zang, J., Matsuki, A., and Trochkine, D.: Mixture state and size of Asian dust particles collected at southwestern Japan in spring 2000, J. Geophys. Res.-Atmos., 108, 4760, https://doi.org/10.1029/2003JD003869, 2003.

Zhang, X., Massoli, P., Quinn, P. K., Bates, T. S., and Cappa, C. D.: Hygroscopic growth of submicron and supermicron aerosols in the marine boundary layer, J. Geophys. Res.-Atmos., 119, 83848399, https://doi.org/10.1002/2013JD021213, 2014.

Zhang, X.-X., Sharratt, B., Liu, L.-Y., Wang, Z.-F., Pan, X.-L., Lei, J.-Q., Wu, S.-X., Huang, S.-Y., Guo, Y.-H., Li, J., Tang, X., Yang, T., Tian, Y., Chen, X.-S., Hao, J.-Q., Zheng, H.-T., Yang, Y.-Y., and Lyu, Y.-L.: East Asian dust storm in May 2017: observations, modelling, and its influence on the Asia-Pacific region, Atmos. Chem. Phys., 18, 8353-8371, https://doi.org/10.5194/acp18-8353-2018, 2018.

Zhu, Y., Li, K., Shen, Y., Gao, Y., Liu, X., Yu, Y., Gao, H., and Yao, X.: New particle formation in the marine atmosphere during seven cruise campaigns, Atmos. Chem. Phys., 19, 89-113, https://doi.org/10.5194/acp-19-89-2019, 2019. 